LA-UR-97- 2048

Approved for public release; distribution is unlimited

\title{
Title: New Anion-Exchange Polymers for Improved Separations
}

Author(s): Gordon D. Jarvinen, Mary E. Barr and

Submitted to: $\mid$\begin{tabular}{l|l} 
S. Fredric Marsh, NMT-6 \\
DOE Office of Scientific and Technical Information (OSTI)
\end{tabular}

DISCLAIMER

This report was prepared as an account of work sponsored by an agency of the United States Government. Neither the United States Government nor any agency thereof, nor any of their emplcyees, makes any warranty, express or implied, or assumes any legal liability or responsibility for the accuracy, completeness, or usefulness of any information, apparatus, product, or process disclosed, or represents that its use would not infringe privately owned rights. Reference herein to any specific commercial product, process, or service by trade name, trademark, manufacturer, or otherwise does not necessarily constitute or imply its endorsement, recommendation, or favoring by the United States Government or any agency thereof. The views and opinions of authors expressed herein do not necessarily state or reflect those of the United States Government or any agency thereof.

\section{Los Alamos}

NATIONAL LABORATORY

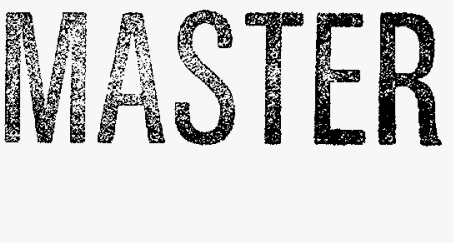

Los Alamos National Laboratory, an affirmative action/equal opportunity employer, is operated by the University of California for the U.S. Department of Energy under contract W-7405-ENG-36. By acceptance of this article, the publisher recognizes that the U.S. Government retains a nonexclusive, royaltytree license to publish or reproduce the published form of this contribution, or to allow others to do so, Ior U.S. Government purposes. Los Alamos National Laboratory requests that the publisher identify this article as work performed under the auspices of the U.S. Department of Energy. Los Alamos National Laboratory strongly supports academic freedom and a researcher's right to publish; as an institution, however, the Laboratory does not endorse the viewpoint of a publication or guarantee its technical correctness. 


\section{DISCLAMMER}

Portions of this document may be illegible in electronic image products. Images are produced from the best available original document. 


\title{
New Anion-Exchange Polymers for Improved Separations
}

\author{
Gordon D. Jarvinen* \\ Mary E. Barr \\ S. Fredric Marsh
}

\begin{abstract}
This is the final report of a one-year, Laboratory Directed Research and Development (LDRD) project at the Los Alamos National Laboratory (LANL). The objective of this work is to improve our understanding of how the structure of a new class of anion-exchange polymers controls the binding of anionic actinide complexes from solution. This kind of fundamental data is needed to develop practical separation systems that will reduce the cost of actinide processing operations within the DOE complex. In addition, anion exchange is widely used in industry and these new materials have potentially much broader applications. Several new series of bifunctional anion-exchange polymers have been designed, synthesized and tested for their ability to remove plutonium(IV), americium(III), and uranium(VI) from nitric acid. The polymers contain a pyridinium site derived from the host poly(4-vinylpyridine) and a second cationic site attached through a chain of two to six methylene groups. The new polymers removed plutonium four to ten times more efficiently than the best commercial materials.
\end{abstract}

\section{Background and Research Objectives}

Anion exchange in nitric acid is the process most frequently used to recover plutonium from a wide range of impure nuclear materials [1]. Plutonium(IV), the most stable oxidation state of plutonium in nitric acid, readily forms an anionic hexanitrato complex that is strongly retained by anion-exchange resins. Anion exchange is attractive for separating plutonium because the $\mathrm{Pu}(\mathrm{IV})$ nitrate complex is very strongly sorbed and few other metal ions form competing anionic nitrato complexes [2].

The major disadvantage of this process has been the unusually slow rate at which the $\mathrm{Pu}$ (IV) nitrate complex is sorbed by the resin [3]. To address this limitation, we previously measured the $\mathrm{Pu}(\mathrm{IV})$ sorption rates of more than 30 commercial and

Principal Investigator, e-mail: gjarvinen@lanl.gov 
experimental resins. The results of that study led us to replace polystyrene gel resin with a macroporous resin, whose more porous structure significantly increased the plutonium sorption rate [4].

Although polystyrene-based anion-exchange resins have been used for many years in the nuclear industry, such polymers can react exothermically with nitric acid under certain conditions. Vinylpyridine polymers, by contrast, are more resistant to radiolytic degradation and chemical attack by nitric acid. Since 1988, Reilly Industries, Inc. has produced Reillex ${ }^{\mathrm{TM}} \mathrm{HPQ}$, a macroporous copolymer of partially $\mathrm{N}$-methylated 4 vinylpyridine and divinylbenzene. For the past seven years, during which Reillex ${ }^{\mathrm{TM}} \mathrm{HPQ}$ has been used in a Los Alamos full-scale plutonium recovery process, this resin has outperformed all other commercial resins, while providing superior resistance to nitric acid and radiation damage [5].

Our goal was to minimize the plutonium content of the liquid and solid waste generated by the plutonium recovery process by increasing the efficiency of the anionexchange resin. Although our previous resin-testing efforts, discussed above, resulted in significant improvements, we hoped to do even better by adopting a more systematic approach to understanding the structure-function relationships of these anion-exchange polymers.

\section{Importance to LANL's Science and Technology Base and National R\&D Needs}

The processing of plutonium and other actinides is a crucial part of the Laboratory's core technical competencies in nuclear and advanced materials and nuclear weapons science and technology. The work described in this report contributes to the Laboratory's Plutonium Future tactical goal, as well as to the Laboratory's mission in Science-Based Stockpile Stewardship and Management. The development of plutonium management strategies and technologies that minimize environmental impacts and life-cycle costs is an important part of both of these institutional objectives.

Partly as a result of this LDRD effort, we were successful in obtaining funding for further R\&D work with these new polymers from the Environmental Management Science Program of the DOE. This program was established to encourage innovative basic research that will contribute to DOE environmental management and restoration actions that will decrease risk for the public and workers, provide opportunities for major cost reductions, and reduce the time required to achieve DOE mission goals. 


\section{Scientific Approach and Accomplishments}

In preliminary studies, we used visible, nuclear magnetic resonance, and extended $\mathrm{x}$-ray absorption fine structure spectroscopic techniques to help identify the plutonium complexes involved in the anion-exchange process [6.7]. Our investigations indicated that the uncharged tetranitrato complex of Pu(IV) is most likely to interact with the anionexchange resin, even though this neutral complex must acquire two more nitrate groups to become a divalent anion during the sorption process. Once we had indications that this complex was a key to the anion-exchange process, we tried to envision an anion-exchange structure into which a plutonium tetranitrato complex would "fit" most easily.

One possibility was a bifunctional resin structure that provides two anion-exchange sites separated by a fixed distance. We tested this concept by synthesizing a series of bifunctional resins in which a second cationic group was attached through an alkylene chain to the pyridine nitrogen of a commercial Reillex ${ }^{\mathrm{TM}} 4024$-vinylpyridine polymer resin. The new materials were prepared by Prof. Richard A. Bartsch and his coworkers at Texas Tech University. The synthetic work was funded through Nuclear Materials Technology Division programmatic support and the Amarillo National Resource Center for Plutonium.

Several new series of bifunctional anion exchange polymers were designed, synthesized and tested for their ability to remove plutonium(IV), americium(III), and uranium(VI) from nitric acid. The polymers contain a pyridinium site derived from the host poly(4-vinylpyridine) and a second cationic site attached through a chain of two to six methylene groups that was either trimethylammonium, pyridinium, or trimethylphosphonium. The new polymers removed plutonium four to ten times more efficiently than the best commercial materials presently available. The sorption kinetics and distribution coefficients for plutonium(IV) were generally best when the two cationic sites were separated by a five methylene spacer. The order of affinity for plutonium from $7 \mathrm{M}$ nitric acid was pyridinium $>$ phosphonium $>$ trimethylammonium. Replacing the central methylene group in a five unit spacer with an ether oxygen further enhanced the sorption of plutonium. More detail in the results of these studies are found in the paper listed under Publications below.

These new polymers offer the prospect of removing plutonium more effectively from many process and waste solutions, while decreasing the volume of secondary waste generated. Los Alamos has a patent pending that covers the resins described above and other bifunctional resins not included here and is currently negotiating a license with a prospective industrial partner. Anion exchange is widely used in industry and these new 
materials have potentially much broader application in areas such as water treatment, pollution control technology, and purification of chemical products.

\section{Publications}

1. Marsh, S. F., Jarvinen, G. D. and Bartsch, R. A., "New bifunctional anionexchange resins for nuclear waste treatment," Reactive Polymers, in press.

\section{References}

[1] Ryan, J.L. and Wheelwright, E. J., "The recovery, purification, and concentration of plutonium by anion exchange in nitric acid," U.S. Atomic Energy Commission report HW-55893(del), (1959).

[2] Faris, J. P. and Buchanan, R. F., "Applications of anion-exchange spectrographic procedures in nitric acid medium," U.S. Atomic Energy Commission report TID7606, p. 185 (1960).

[3] Streat, M. "Kinetics of slow diffusing species in ion exchangers," Reactive Polymers, 2, 79 (1984).

[4] Marsh, S. F., "Improved recovery and purification of plutonium at Los Alamos using macroporous anion exchange resin," Los Alamos National Laboratory report LA10906, May (1987).

[5] Marsh, S. F., "The effects of in situ alpha-particle irradiation on six strong-base anion exchange resins," Los Alamos National Laboratory report LA-12055, April (1991).

[6] Marsh, S. F., Day, R. S. and Veirs, D. K., "Spectrophotometric investigation of the plutonium nitrate species sorbed by ion exchange resins," Los Alamos National Laboratory report LA-12070, June (1991).

[7] Veirs, D. K., Smith, C. A., Berg, J. H., Zwick, B. D., Marsh, S. F., Allen, P. and Conradson, S. D., "Characterization of the nitrate complexes of $\mathrm{Pu}(\mathrm{IV})$ using absorption spectroscopy, 15N NMR, and EXAFS," J. Alloys Compounds, 213/214, 328 (1994). 